\section{New Directions in Gold Catalysis}

\author{
Graham J. Hutchings \\ Department of Chemistry, Cardiff University, \\ P.O. Box 912, Cardiff, UK, CF10 3TB
}

In the last decade there has been an explosion in the interest shown in catalysis by gold. It is now recognised that gold has unique properties as a catalyst for many reactions with pre-eminence in heterogeneous catalytic oxidation. This paper sets out the general content of a keynote lecture delivered at the second world congress on gold in Vancouver in 2003. The background to this significant interest is discussed and the early work in the field is placed in context. The current areas of interest are described and two reactions, namely the oxidation of glycerol to glyceric acid and the formation of hydrogen peroxide from the oxidation of molecular hydrogen, are discussed. The prospects for future discoveries are also considered.

\footnotetext{
About the Author

Professor Graham Hutchings is currently Head of the Department of Chemistry at the University of Cardiff. He has been actively involved in catalysis by gold since 1982 when he was working in South Africa for AECI Ltd on the topic of improved catalysts for vinyl chloride synthesis.
}

\section{Background}

On Sunday 28th September 2003 over 200 delegates met in Vancouver to discuss the relatively new field of catalysis by gold that has emerged onto the scientific scene in the last few years. It should be recognised that there is a great deal of excitement in the realisation that gold has previously unrecognised properties. The discovery in the 1980's that finely supported divided nanoparticles of gold could act as catalysts for reactions at low temperatures has to be one of the most fascinating observations of the late twentieth century, since hitherto gold had been considered unreactive and consequently its chemistry was thought to be particularly unexciting. The new discoveries bring the realisation that gold, in an appropriate form, is perhaps the most interesting metal in the Periodic Table with respect to its potential to act as a catalyst. It is against this background that the delegates met in Vancouver both to review the scene and to consider new possibilities. My role as opening speaker was to set the scene, review the early discoveries and to describe the current areas of debate, and the intention of this paper is to briefly summarise this keynote lecture.

As I was speaking first I thought it would be wise to try to find a link between Vancouver and gold, since none was immediately apparent to me. Although, Canada has significant gold mining it is not really near Vancouver, and Vancouver is not associated with any of the famous gold rushes that punctuate the history of the western seaboard of the US and Canada. Vancouver, of course, was a famous British seaman who made several voyages to the western coasts of Canada and Alaska in the 1790's in search of the fabled North West passage that would link the Pacific and Atlantic oceans. On one of these visits to the Alaskan coast he noted the existence of "high stupendous mountains covered with snow". Vancouver was the first person to remark on the existence of magnificent mountain ranges in the interior of Alaska. In this sense he was lucky, and luck is certainly something that is required if you are to make a significant discovery. Many years earlier von Bering had established beyond doubt that Russian and the US landmasses were not connected and are separated by a body of water that now bears his name. However, he had sailed within a few miles of the Alaskan coast and not spotted it. He missed his chance of discovering Alaska, something which annoyed him for the rest of his life. Indeed he died on a return voyage to the Bering Straights some years later as he had wished to visit Alaska.

The mountains that Vancouver had spotted were subsequently confirmed to exist by the expedition of Van Wrangell in 1839. The mountain shown, in Figure 1, is 20,320 feet high and is the tallest mountain in the North American continent. He named the mountain Tanada, a name still 


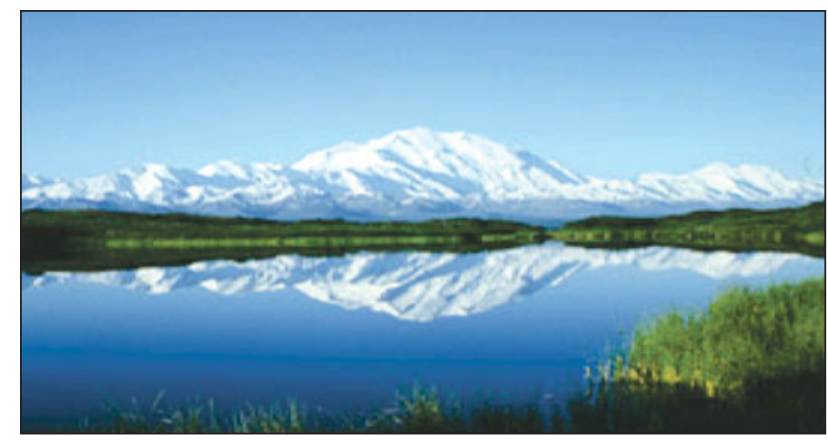

Figure 1

Mount McKinley in the Denali National Park, Alaska, USA

given to one of the fast flowing rivers in this region of Alaska. However, in 1847 Zagoskin, another Russian explorer could find no traces of these mountains. Consequently, Tanada was removed from all maps. It was not until 1896, a full century after Vancouver had observed the high mountains, that William Dickey finally confirmed the presence of the mountains and renamed it Mount McKinley in honour of the future President of the US who championed the use of the gold standard for currency. Here, then, is the link between Vancouver and gold. There is, however, a message for all of us in this story of the lost mountain. After all how can anyone miss seeing a 20,320 foot mountain when they are specifically looking for it. We do not associate geographers and explorers with reproducibility problems that scientists are often beset with. The answer is relatively simple and concerns observation techniques, which is also often at the core of problems of scientific dispute. Mount McKinley is only visible from close range for a very few days in each season that anyone would venture into the interior of Alaska. You have to be really lucky to see it since it is so high that it creates its own weather system that shrouds it almost continually in clouds.

\section{Early discoveries of the unique high activity of gold as a catalyst}

Until the 1980's gold was considered to be an inactive metal for catalysis, and even some of the attributed effects were sometimes ascribed to the presence of impurities in the gold samples being used. Bond and co-workers (1) did demonstrate that very small gold particles supported on silica could give interesting catalytic performance for hydrogenation, but until very recently the use of gold as a selective hydrogenation catalyst has received little attention (2). There were, however, two significant observations that highlighted the special attributes of gold as a heterogeneous catalyst:

- Haruta : discovery that supported Au catalysts are very active for low temperature CO oxidation (3).
- Hutchings : prediction that Au would be best catalyst for ethyne hydrochlorination (4).

\section{Ethyne hydrochlorination}

In the early 1980's one of the routes to the synthesis of vinyl chloride was based on ethyne hydrochlorination using mercuric chloride supported on carbon as catalyst. This catalyst suffers from deactivation due to sublimation of the active component and so a replacement catalyst that was more stable was an important research goal. Shinoda (5) demonstrated that a range of metal chlorides supported on carbon could give a spectrum of activities. The data were correlated with the electron affinity of the cation (Figure 2) but using this correlation the data could not be used predictively. Hutchings (4) recognised that the reaction was not a one electron process, as defined by the electron affinity, but was more likely to involve two $\pi$ electrons of the ethyne and hence, as most of the cations in the data set were divalent, the standard electrode potential was a more viable parameter with which to correlate the data (Figure 3). The plot of conversion against the standard electrode potential gives a smooth curve and this predicts that gold, and more importantly $\mathrm{Au}^{3+}$, will be the best catalyst for this reaction, and this was confirmed in subsequent research (6-8). Although the gold catalysts were much more stable than the

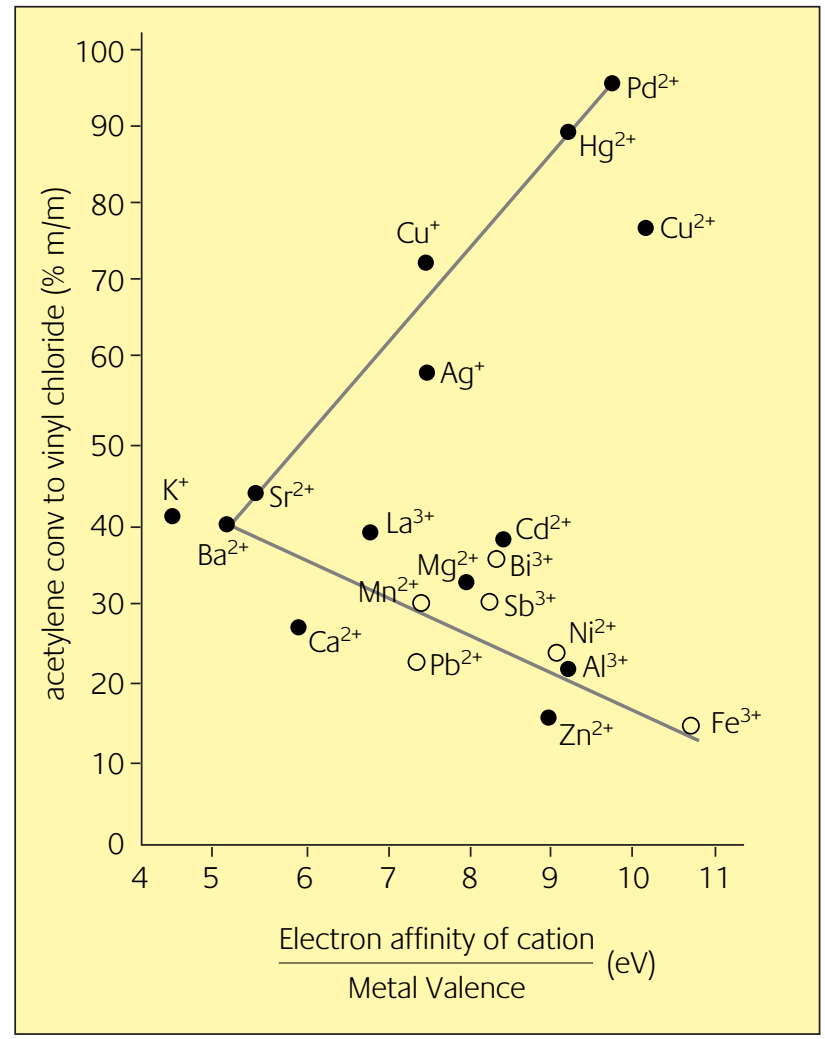

Figure 2

Correlation of activity for ethyne hydrochlorination with the electron affinity of the cation divided by the metal valence (5) 


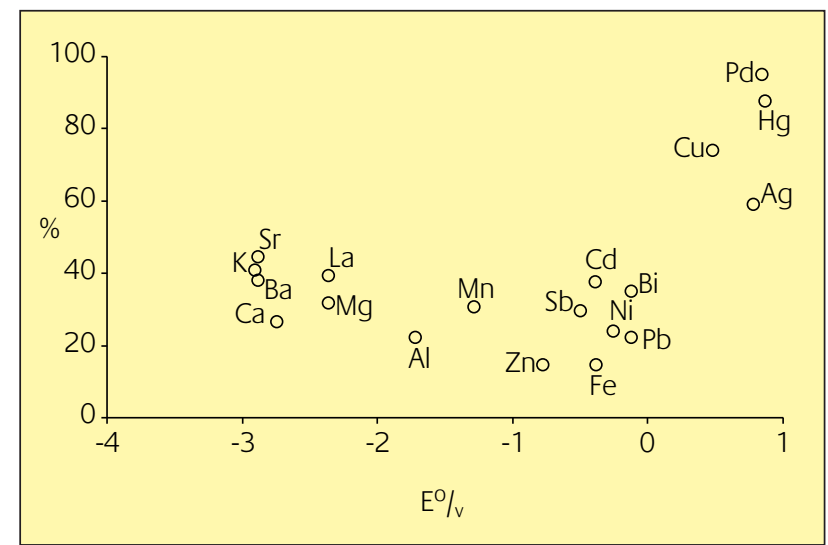

Figure 3

Correlation of activity for ethyne hydrochlorination with the standard electrode potential (4)

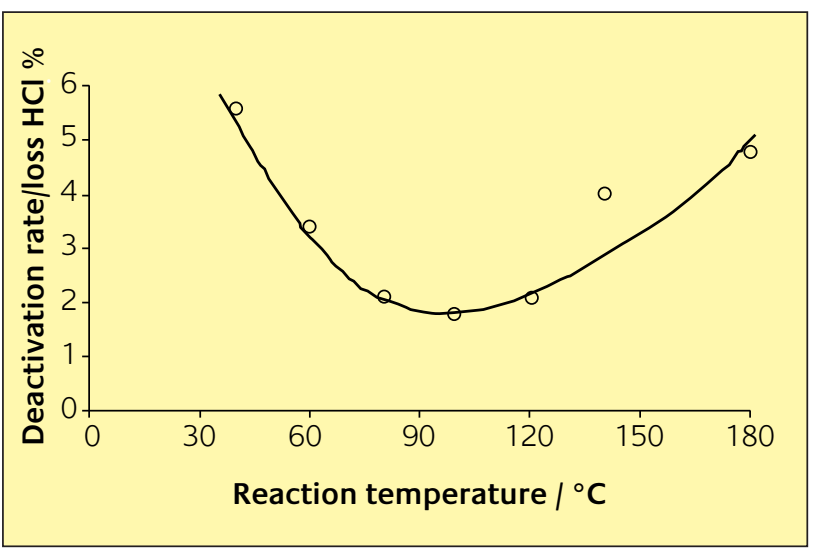

\section{Figure 4}

Deactivation rate of Au/carbon catalysts for ethyne hydrochlorination as a function of temperature $\left(0.0005 \mathrm{~mol} \mathrm{Au} / 100 \mathrm{~g}\right.$ catalyst, $\mathrm{C}_{2} \mathrm{H}_{2}: \mathrm{HCl}=$ 1:1.2) (6)

supported mercuric chloride catalysts, they still deactivated slowly with time and the rate of deactivation is dependent on temperature (Figure 4). The deactivation rate was at a minimum at $100^{\circ} \mathrm{C}$, but at this temperature the catalyst was not sufficiently active and temperatures of ca. $180^{\circ} \mathrm{C}$ are preferred. At temperatures below $100^{\circ} \mathrm{C}$ the deactivation was caused by deposition of polymeric carbonaceous materials and at higher temperatures the deactivation was caused by reduction of $\mathrm{Au}^{3+}$ to $\mathrm{Au}^{0}$ as shown by detailed ${ }^{197} \mathrm{Au}$ Mössbauer spectroscopy (Figure 5). This was a key observation and meant that the deactivation could be arrested by in situ reactivation by co-feeding dilute $\mathrm{NO}$ in with the reactor feedstock. This had no effect on catalyst selectivity but did stop deactivation (Figure 6). This was the first demonstration of in situ reactivation of gold catalysts and also the first clear demonstration that cationic gold can be an effective heterogeneous catalyst.

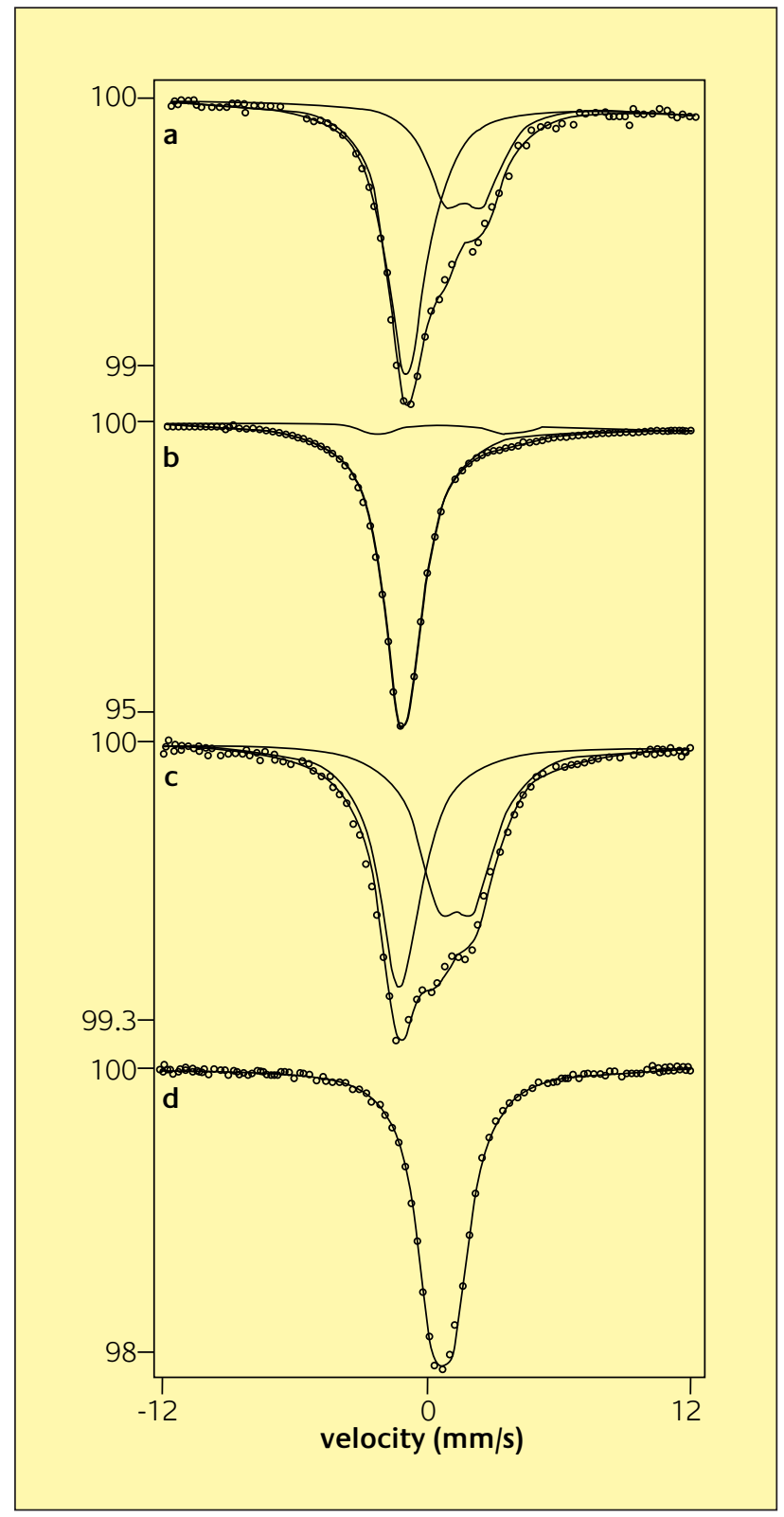

\section{Figure 5}

${ }^{197}$ Au Mössbauer spectra of; (a) 2\% $\mathrm{HAuCl}_{4} / \mathrm{C}$ adsorbed on activated carbon from an aqua regia solution, (b) the same catalyst after deactivation at $180^{\circ} \mathrm{C}$ for $6 \mathrm{~h}\left(\mathrm{CHSV}=1140 \mathrm{~h}^{-1}, \mathrm{C}_{2} \mathrm{H}_{2}: \mathrm{HCl}=1: 1.1\right)$, (c) a sample of the same type after reactivation by boiling in aqua regia, and (d) crystalline $\mathrm{HAuCl}_{4} . \mathrm{XH}_{2} \mathrm{O}$ (7)

\section{CO Oxidation}

Also in the early 1980's Haruta (3) recognised that supported gold nano-crystals can be highly effective catalysts for the oxidation of $\mathrm{CO}$ at very low temperatures (Figure 7) and in particular at temperatures below $0^{\circ} \mathrm{C}$. This is a surprisingly high activity and is not replicated by other metals. This low temperature activity has spurred a great deal of the current research interest in gold today. 


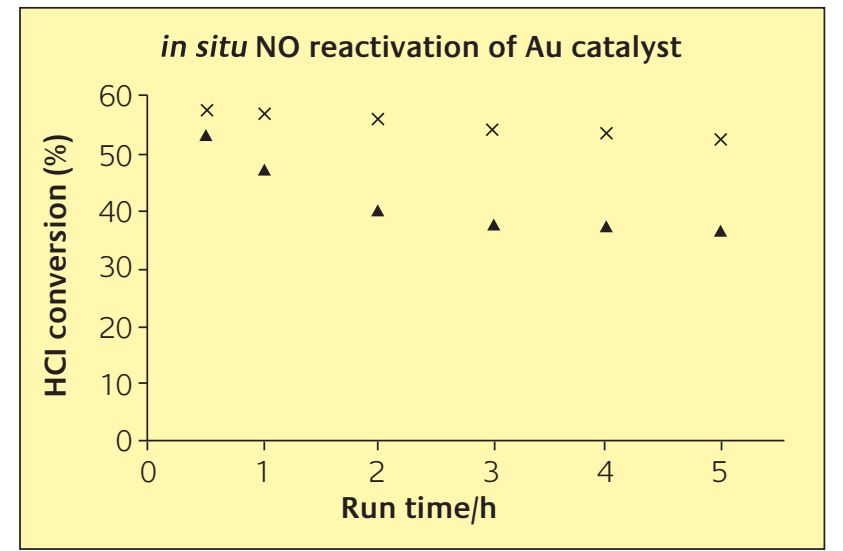

Figure 6

Effect of in situ reactivation of 2 wt\% Au/C catalyst at $180^{\circ} \mathrm{C}$. Key : $\square$ $\mathrm{C}_{2} \mathrm{H}_{2} / \mathrm{HCl} / \mathrm{N}_{2}, \times 0.42$ vol\% NO cofed with reactants (7)

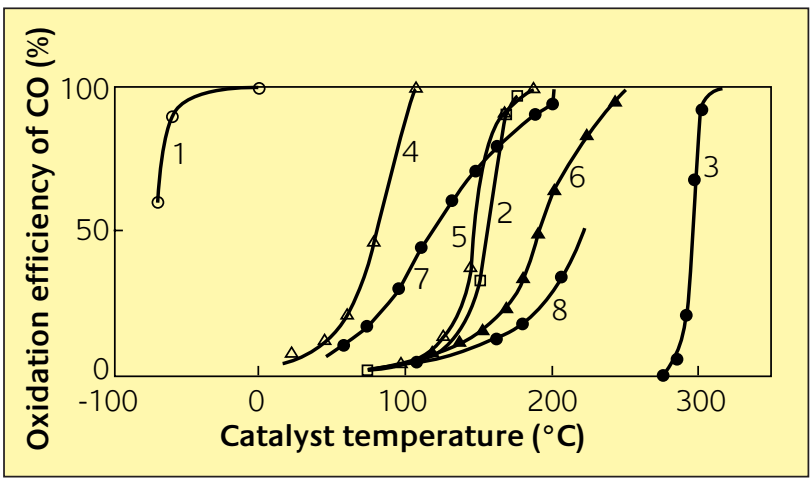

Figure 7

CO conversion over various catalysts as a function of temperature. $\mathbf{1}$, $\mathrm{Au} / \alpha-\mathrm{Fe}_{2} \mathrm{O}_{3}\left(\mathrm{Au} / \mathrm{Fe}=1 / 19\right.$, co-precipitation, $\left.400^{\circ} \mathrm{C}\right) ; 2$, $0.5 \mathrm{wt} \% \mathrm{Pd} / \gamma^{-}$ $\mathrm{Al}_{2} \mathrm{O}_{3}$ (impregnation, $300^{\circ} \mathrm{C}$ ); 3, Au fine powder; 4, $\mathrm{CO}_{3} \mathrm{O}_{4}$ (carbonate, $400^{\circ} \mathrm{C}$ ); 5, NiO (hydrate, $200^{\circ} \mathrm{C}$ ); $6, \alpha-\mathrm{Fe}_{2} \mathrm{O}_{3}$ (hydrate, $400^{\circ} \mathrm{C}$ ); 7, 5 wt\% $\mathrm{Au} / \alpha-\mathrm{Fe}_{2} \mathrm{O}_{3}$ (impregnation, $200^{\circ} \mathrm{C}$ ); $8,5 \mathrm{wt} \% \mathrm{Au} / \gamma-\mathrm{Al}_{2} \mathrm{O}_{3}$ (impregnation, $200^{\circ} \mathrm{C}$ ). (Haruta et al, Journal of Catalysis 115(2), (1989) 301)

\section{Catalysis by gold: current statistics on papers and patents}

Since the initial discoveries outlined in the previous section there has been an explosion of interest in the study of catalysis by gold (Figure 8 ). The rate of academic publications, shown in red, are climbing almost exponentially as interest in the field has dramatically increased during the 1990's and at the present rate of publication 600-700 papers can conservatively be expected in the current decade. Patent activity, shown in blue was not much in evidence before 1990 but has climbed since then and is fairly steady. Catalysis by gold is clearly a fast growing subject but at the present time a lot of this activity is just replicating a large portion of the earlier work and only a few researchers are opening up new areas of study.

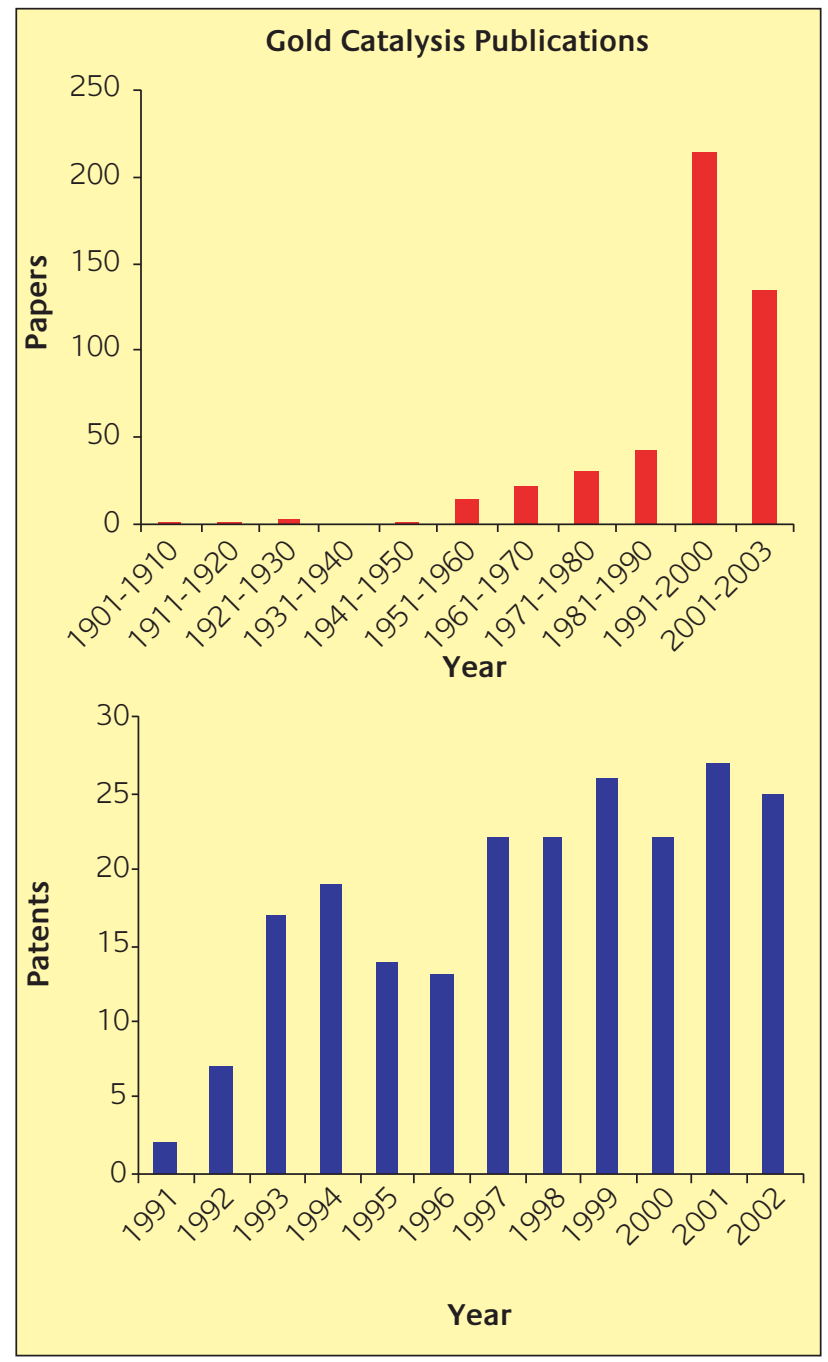

Figure 8

Publications on gold catalysis, red academic publications, blue patents

\section{CO oxidation: comments on the current research perspectives}

CO oxidation is now being used by many researchers as a standard test reaction, and this early work has been extensively reviewed $(9,10)$. This early research indicates that catalysts must be prepared in a particular way using precipitation, and the impregnation methods used resulted in very poor catalysts. Many of the active catalysts are typically found to consist of small crystallites, 2-4 nm in diameter, of gold supported on an oxide. There has been much debate concerning the nature of the active site for these catalysts and, recently, Bond and Thompson (10) have proposed a model where Au atoms at the interface between the Au particle and the oxide are the active oxidation centres (Figure 9). However, it remains unclear whether $\mathrm{Au}^{3+}$ or $\mathrm{Au}^{0}$ is the active form of gold.

To demonstrate the potential complexity of supported Au catalysts and the interplay between catalyst activity and the 


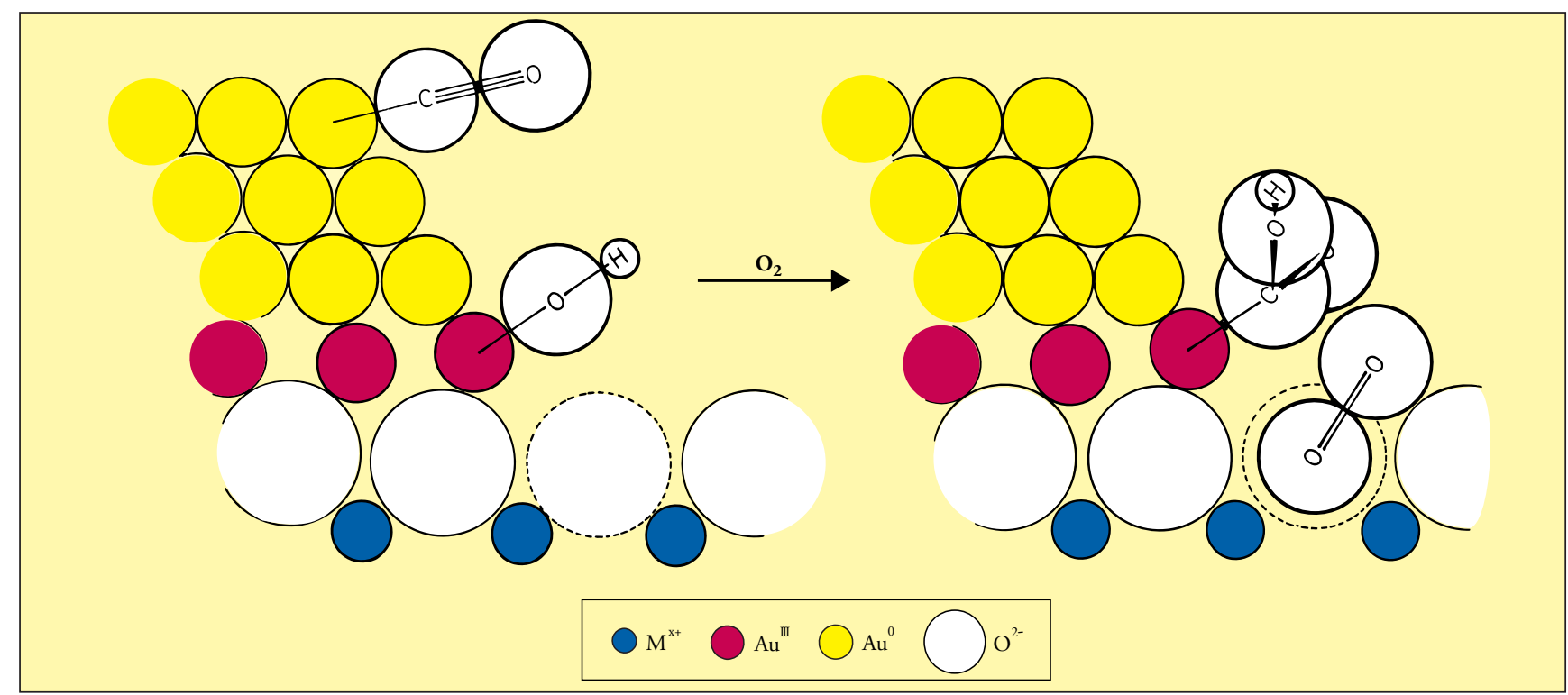

\section{Figure 9}

Schematic representation of the mechanism of CO oxidation (10)

preparation method, the results from studies on $\mathrm{Au} / \mathrm{ZnO}$ (11) and $\mathrm{Au} / \alpha-\mathrm{Fe}_{2} \mathrm{O}_{3}$ (12) catalysts can be considered (both catalysts contain 5 wt\% Au and were prepared by a similar co-precipitation procedure). Under appropriate conditions, both catalysts are very active for the oxidation of carbon monoxide to carbon dioxide at $25^{\circ} \mathrm{C}$. However, the Au/ZnO catalyst dried at $120^{\circ} \mathrm{C}$ in air (Figure 10a) is inactive for the reaction, whereas $\mathrm{Au} / \mathrm{ZnO}$ calcined at $400^{\circ} \mathrm{C}$ (Figure 10b) gives $100 \%$ CO conversion. The converse, however, is observed for the $\mathrm{Au} / \alpha-\mathrm{Fe}_{2} \mathrm{O}_{3}$ catalysts, and now the catalyst prepared by drying at $120^{\circ} \mathrm{C}$ (Figure 10C) gives $100 \% \mathrm{CO}$ conversion, whereas $\mathrm{Au} / \alpha-\mathrm{Fe}_{2} \mathrm{O}_{3}$ calcined at $400^{\circ} \mathrm{C}$ (Figure 10d) is inactive. From the TEM micrographs, it is apparent that, in the case of the Au/ZnO catalyst, it is logical to suggest that the small Au crystallites, and possibly the interface with the $\mathrm{ZnO}$, are the active sites. In contrast, a more oxidised form of gold present with sub-nanometer gold particles is the active form of gold for the $\alpha-\mathrm{Fe}_{2} \mathrm{O}_{3}$ supported catalyst. These results indicate that the active site for heterogeneous catalysts may vary with the composition of the catalyst.

This represents the crucial question that remains unanswered by current research, namely the nature of the active species in the catalytic reaction, is it $\mathrm{Au}^{3+}$ to $\mathrm{Au}^{\circ}$ ? $\mathrm{A}$ number of studies have tried to address this. For example, a
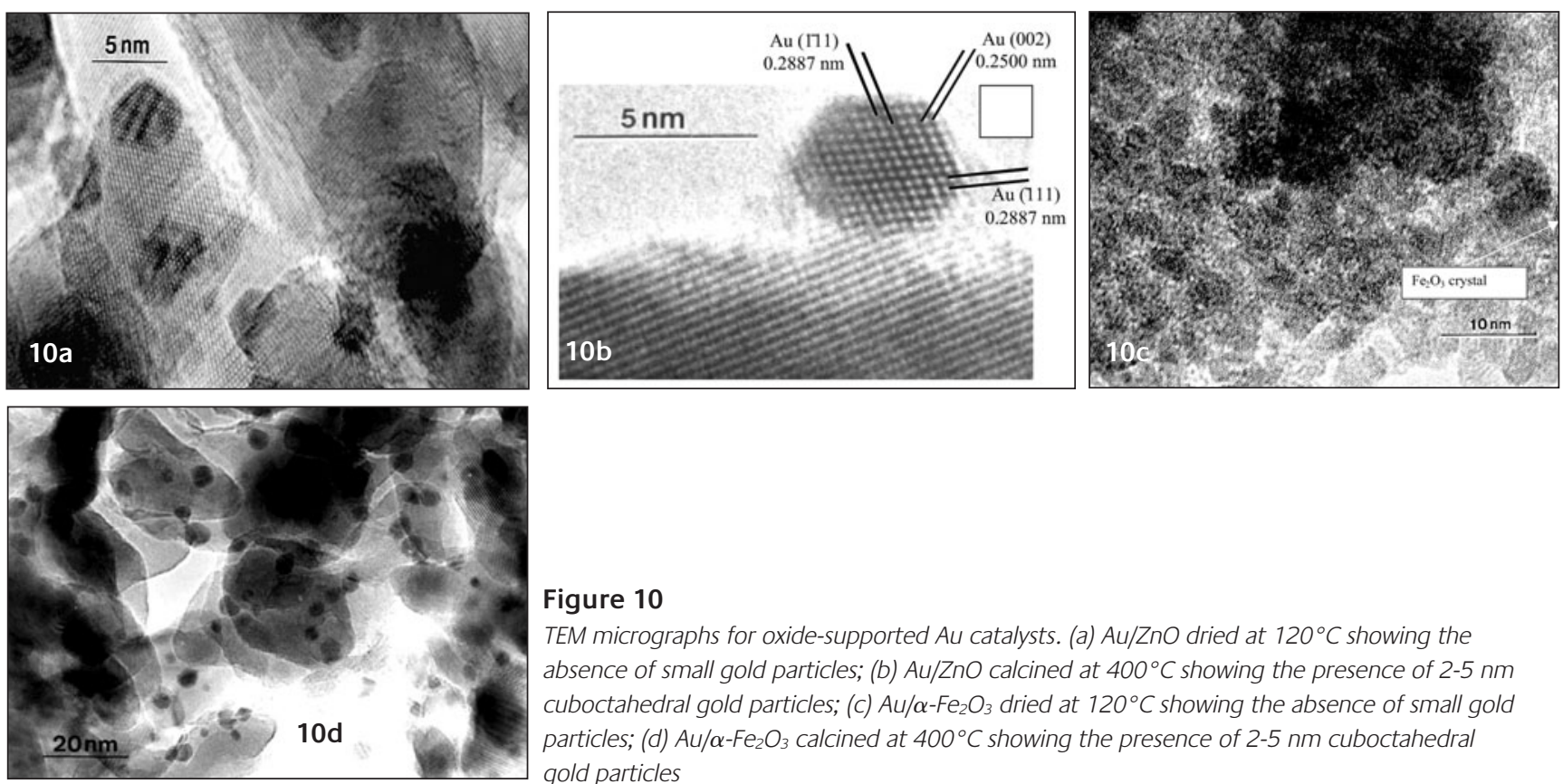

Figure 10

TEM micrographs for oxide-supported Au catalysts. (a) Au/ZnO dried at $120^{\circ} \mathrm{C}$ showing the absence of small gold particles; (b) Au/ZnO calcined at $400^{\circ} \mathrm{C}$ showing the presence of 2-5 nm cuboctahedral gold particles; (c) $\mathrm{Au} / \alpha-\mathrm{Fe}_{2} \mathrm{O}_{3}$ dried at $120^{\circ} \mathrm{C}$ showing the absence of small gold particles; (d) $\mathrm{Au} / \alpha-\mathrm{Fe}_{2} \mathrm{O}_{3}$ calcined at $400^{\circ} \mathrm{C}$ showing the presence of 2-5 nm cuboctahedral gold particles 
number have focused on the role of $\mathrm{Au}^{\circ}$ :

- Goodman and co-workers (13)

3-5 nm Au particles most active for CO oxidation

(Combination of STM / spectroscopy)

Unusual reactivity could be due to quantum size effects

- Boyen et al. (14)

Au particles containing 55 atoms, $1.4 \mathrm{~nm}$ in diameter, extraordinarily stable

$\mathrm{Au}_{55}$ could be active site for $\mathrm{CO}$ oxidation

- Nørskov and co-workers (15)

Energetically favoured reaction path for $\mathrm{CO}$ on $\mathrm{Au}$ particles with 10 atoms

Whereas a number of others have focused on the role of $\mathrm{Au}^{3+}$ :

- Baker (16)

"Explanations of the high catalytic activity of gold particles on the basis of size alone neglect the importance of the underlying support" It is important to consider periphery effects of the small nanoparticles.

- Flytzani-Stephanopoulos and co-workers (17)

Active non-metallic Au and Pt species on ceria-based watergas shift catalysts, comprising nano-crystalline 10\% La-doped $\mathrm{CeO}_{2}(\sim 5 \mathrm{~nm})$, Au added by deposition precipitation calcined $400^{\circ} \mathrm{C}, 10 \mathrm{~h}$, at this stage the Au nanoparticles are mostly 5 $\mathrm{nm}$. Au leached with $2 \% \mathrm{NaCN}$ at room temperature, washed, dried, calcined $400^{\circ} \mathrm{C}, 2$ h. $90 \%$ Au removed, no La or Ce leached and no Au particles remained after $\mathrm{NaCN}$ leaching. However the catalytic activity was retained.
- Gates and Guzman $(18,19)$

$\mathrm{Au}^{3+}$ organometallic complexes used to prepare Au / MgO for hydrogenation of ethene. In situ X-ray absorption spectroscopy

$\mathrm{Au}^{3+}$ active $\mathrm{Au}^{0}$ inactive

- Hutchings $(4,7,8)$

$\mathrm{Au}^{3+}$ in ethyne hydrochlorination catalysts that can be reactivated in situ by NO

- Hutchings and co-workers (12)

$\mathrm{Au}^{3+}$ in $\mathrm{Au} / \mathrm{Fe}_{2} \mathrm{O}_{3}$ catalysts for the oxidation of $\mathrm{CO}$

It is clear that considerable further research is now required to resolve this interesting question concerning the nature of the active site in these high activity gold catalysts. This will be the area to watch in 2004 .

\section{Oxidation of alcohols}

The oxidation of alcohols and polyols to chemical intermediates represents a demanding target and is of immense importance for the production of fine chemicals. Glycerol is a highly functionalised molecule that is readily available from biosustainable sources, for example it can be obtained as a by-product of the utilisation of rape seed and sunflower crops. The ready bioavailability of glycerol makes it a particularly attractive starting point for the synthesis of intermediates, and a large number of products can be obtained from glycerol oxidation (Scheme 1). One of the key problems is the potential complexity of the products that can

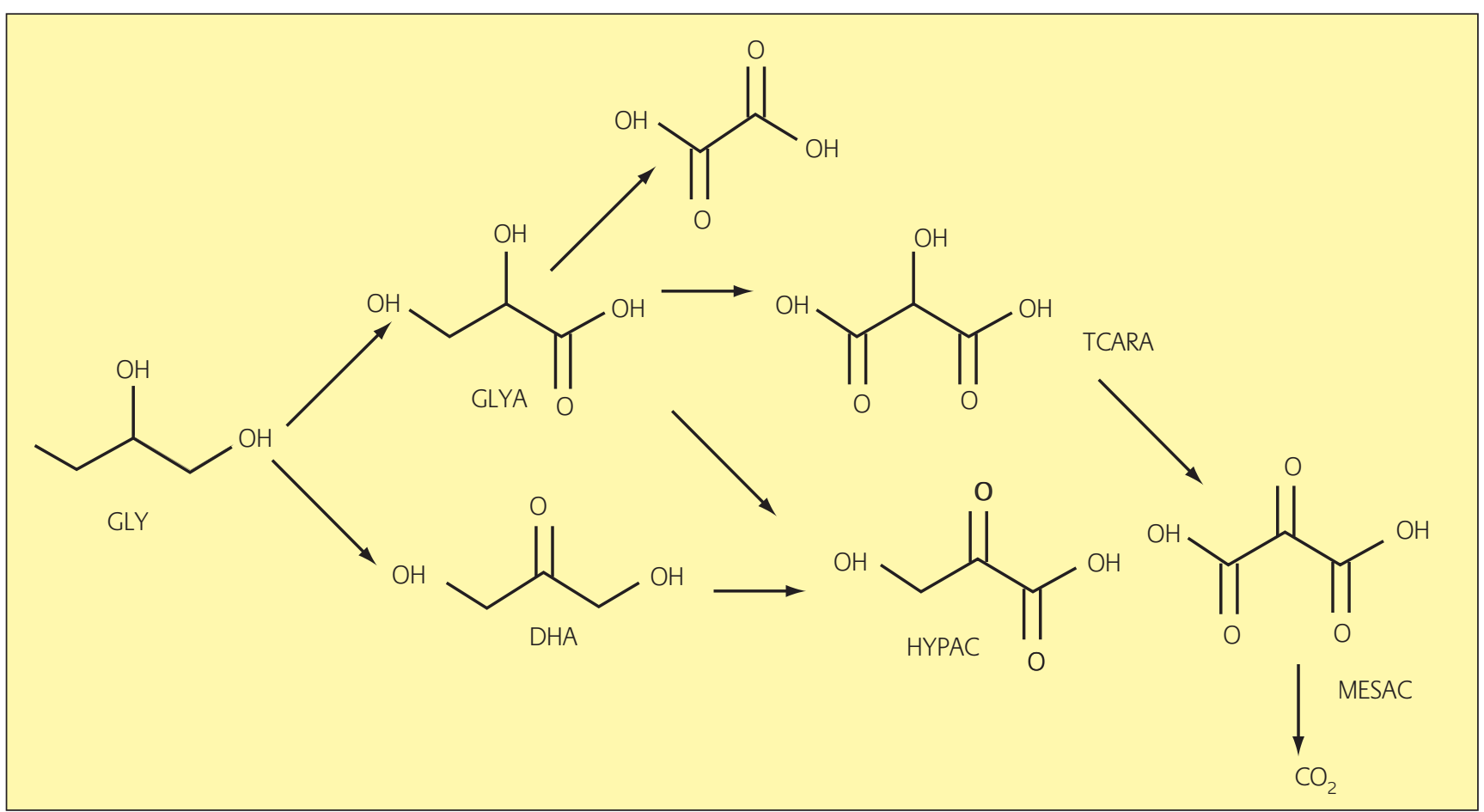

Scheme 1 
be formed and so control of the reaction selectivity by careful design of the catalyst is required. Glycerol oxidation, in aqueous solution, has been extensively studied using supported platinum and palladium catalysts by Gallezot and co-workers (20-22) and Kimura and co-workers $(23,24)$. In general, palladium catalysts were found to be more selective than platinum and high selectivities to either dihydroxyacetone or glyceraldehyde could be obtained by controlling the reaction conditions and, in particular, the $\mathrm{pH}$ of the solution. However, it has been noted that formic acid, probably resulting from the formation of oxalic acid, was also formed and under most conditions this is the major product (25). It is worth noting that, in all these previous studies, mixtures of most of the potential products were formed and often in low selectivity. Hence, glycerol has remained an elusive starting point for the synthesis of chemical intermediates.

In recent years, there has been immense interest in the use of gold catalysts for oxidation reactions (9). Prati and coworkers (26-29) have shown that supported gold nanoparticles can be very effective catalysts for the oxidation of alcohols, including diols. Recently we have extended these studies to show that Au supported on graphite can oxidise glycerol to glycerate with $100 \%$ selectivity using dioxygen as the oxidant under relatively mild conditions $(25,30)$.

The oxidation of glycerol with dioxygen was also investigated using $1 \mathrm{wt} \% \mathrm{Au} / \mathrm{C}$ catalysts in an autoclave and the results are given in Table $1 . \mathrm{NaOH}$ was added as a base since, in the absence of $\mathrm{NaOH}$, no glycerol conversion was observed. In addition, as noted earlier, the carbon supports were also inactive for glycerol oxidation under these conditions, even when $\mathrm{NaOH}$ was present. For all the data presented in Table 1, the carbon mass balance was 100\% indicating that, under these conditions, supported $\mathrm{Au} / \mathrm{C}$ catalysts are extremely selective for this reaction and no $C_{1}$ or $\mathrm{C}_{2}$ by-products were detected. In addition, it is apparent that the selectivity to glyceric acid and the glycerol conversion are very dependent upon the glycerol/NaOH ratio. In general, with high concentrations of $\mathrm{NaOH}$, exceptionally high selectivities to glyceric acid can be observed. However, decreasing the concentration of glycerol, and increasing the mass of the catalyst and the concentration of oxygen, leads to the formation of tartronic acid via consecutive oxidation of glyceric acid. Interestingly, this product is stable with these catalysts. It is apparent that, with careful control of the reaction conditions, $100 \%$ selectivity to glyceric acid can be obtained with $1 \mathrm{wt} \% \mathrm{Au} / \mathrm{C}$. For comparison, the supported $\mathrm{Pd} / \mathrm{C}$ and $\mathrm{Pt} / \mathrm{C}$ always gave other $\mathrm{C}_{3}$ and $\mathrm{C}_{2}$ products in addition to glyceric acid and, in particular, also gave some $C_{1}$ by-products. In a final set of experiments, catalysts with lower Au concentrations were investigated. For catalysts containing 0.25 or 0.5 wt\% Au supported on graphite, lower glycerol conversions were observed (18\% and $26 \%$ respectively as compared to $54 \%$ for 1 wt $\%$ Au/graphite under the same conditions) and lower selectivities to glyceric acid were also observed. The previous studies for diol oxidation by Prati and co-workers (26-29) have also shown that the conversion is dependent on the Au loading upon the support. This is possibly due to a particle size effect of the Au nanoparticles on the support. For gold as a CO oxidation catalyst, it has been shown that the activity is highly dependent on the particle size, and the optimum size is ca. 2-4 nm (9). In view of this, we characterised the Au supported catalysts using TEM. In the $1 \mathrm{wt} \%$ Au/graphite specimen, Au particles as small as $5 \mathrm{~nm}$ and as large as $50 \mathrm{~nm}$ in diameter were detected. The majority, however, were about $25 \mathrm{~nm}$ in size and were multiply twinned in character. Decreasing the loading to 0.5 wt $\%$ or 0.25 wt $\%$ did not appreciably change the particle size distribution; the particle number density per unit area was observed to decrease proportionately however, which may be correlated to the decrease in glycerol

\section{Table 1}

Oxidation of glycerol using 1 wt\% Au/C catalysts

\begin{tabular}{|c|c|c|c|c|c|c|c|c|}
\hline \multirow[b]{2}{*}{ Catalyst } & \multirow[b]{2}{*}{$\begin{array}{c}\text { Glycerol } \\
\text { mmol }\end{array}$} & \multirow[b]{2}{*}{$\begin{array}{l}\mathrm{Po}_{2} \\
\text { bar }\end{array}$} & \multirow[b]{2}{*}{$\begin{array}{c}\text { Glycerol/metal } \\
\text { mol ratio }\end{array}$} & \multirow[b]{2}{*}{$\begin{array}{l}\mathrm{NaOH} \\
\mathrm{mmol}\end{array}$} & \multirow[b]{2}{*}{$\begin{array}{c}\text { Glycerol } \\
\text { conversion (\%) }\end{array}$} & \multicolumn{3}{|c|}{ Selectivity (\%) } \\
\hline & & & & & & $\begin{array}{l}\text { Glyceric } \\
\text { acid }\end{array}$ & Glyceraldehyde & $\begin{array}{c}\text { Tartronic } \\
\text { acid }\end{array}$ \\
\hline $\begin{array}{l}1 \text { wt } \% \text { Au/activated } \\
\text { carbon }\end{array}$ & 12 & 3 & $538^{b}$ & 12 & 56 & 100 & 0 & 0 \\
\hline 1 wt\% Au/graphite & 12 & 3 & $538^{\mathrm{b}}$ & 12 & 54 & 100 & 0 & 0 \\
\hline 1 wt\% Au/graphite & 12 & 6 & $538^{b}$ & 12 & 72 & 86 & 2 & 12 \\
\hline 1 wt\% Au/graphite & 12 & 6 & $538^{b}$ & 24 & 58 & 97 & 0 & 3 \\
\hline 1 wt\% Au/graphite & 6 & 3 & $540^{c}$ & 12 & 56 & 93 & 0 & 7 \\
\hline 1 wt\% Au/graphite & 6 & 3 & $540^{c}$ & 6 & 43 & 80 & 0 & 20 \\
\hline 1 wt\% Au/graphite & 6 & 3 & $214^{d}$ & 6 & 59 & 63 & 0 & 12 \\
\hline 1 wt\% Au/graphite & 6 & 3 & $214^{d}$ & 12 & 69 & 82 & 0 & 18 \\
\hline 1 wt\% Au/graphite & 6 & 6 & $214^{d}$ & 6 & 58 & 67 & 0 & 33 \\
\hline 1 wt\% Au/graphite & 6 & 6 & $214^{d}$ & 12 & 91 & 92 & 0 & 6 \\
\hline 1 wt\% Au/graphite & 6 & 6 & $214^{d}$ & 0 & 0 & & & \\
\hline
\end{tabular}

a $60^{\circ} \mathrm{C}, 3 \mathrm{~h}, \mathrm{H}_{2} \mathrm{O}$ (and $20 \mathrm{ml}$ ), stirring speed $1500 \mathrm{rpm} ;{ }^{\mathrm{b}} 220 \mathrm{mg}$ catalyst; ${ }^{\mathrm{c}} 217 \mathrm{mg}$ catalyst; ${ }^{\mathrm{d}} 450$ mg catalyst 


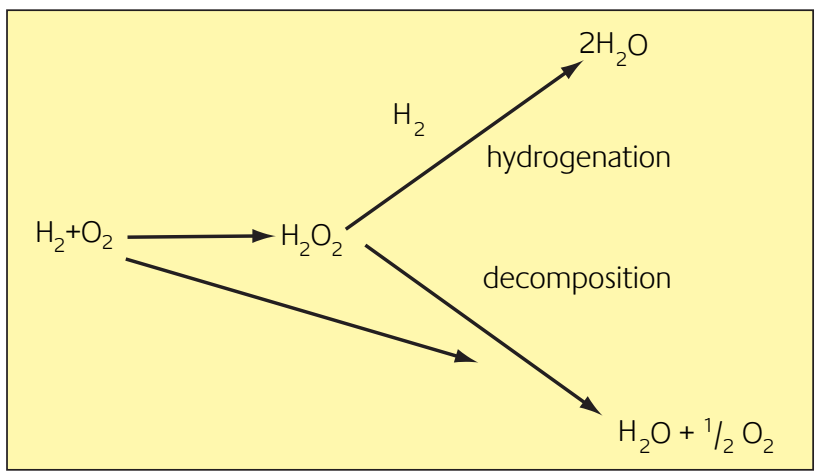

Scheme 2

conversion and selectivity to glyceric acid. It is interesting to note that the Au particles were considerably larger than the 2-4 nm size that is considered to be optimal for low temperature CO oxidation, yet they were still highly active for the glycerol to glyceric acid reaction.

The role of $\mathrm{OH}^{-}$requires further comment since the presence of $\mathrm{OH}^{-}$is essential to observe any glycerol oxidation using the $\mathrm{Au} / \mathrm{C}$ catalysts. It is proposed that, in the absence of a base, the initial dehydrogenation of glycerol, via $\mathrm{H}$-abstraction, which must be the first step in the oxidation process, is not possible for the $\mathrm{Au} / \mathrm{C}$ catalyst. In the presence of base, the $\mathrm{H}^{+}$is readily abstracted from one of the primary hydroxyl groups of glycerol to form glycerate, thereby overcoming the rate-limiting step of the alternative oxidation pathway.

\section{Production of hydrogen peroxide by the oxidation of molecular hydrogen}

Recently, there has been much interest in the design of new heterogeneous catalysts for selective oxidation under ambient conditions, and these typically use hydrogen peroxide as the oxidant (31-33). At present, hydrogen peroxide is produced by the sequential hydrogenation and oxidation of alkyl anthraquinone (34) and global production is ca. $1.9 \times 10^{6}$ tonnes per annum. This process is currently only economic on a large scale (4-6 $\left.\times 10^{4} \mathrm{tpa}\right)$, whereas it is often required practically on a much smaller scale. In view of this, there is considerable interest in the direct manufacture of hydrogen peroxide from the catalysed reaction of hydrogen and oxygen $(35,36)$. At present, some success has been achieved using Pd as a catalyst, especially when halides are used as promoters $(37,38)$. Supported Au catalysts have been investigated for the oxidation of propene to propene oxide using $\mathrm{O}_{2} / \mathrm{H}_{2}$ mixtures (39), and it is considered that a surface hydroperoxy species may be formed as the oxidant. We have found that supported Au catalysts can be very effective for the synthesis of hydrogen peroxide $(40,41)$ and, furthermore, the rate of hydrogen peroxide formation can be significantly enhanced by the use of a supported Au/Pd alloy. Our initial approach to the design of a direct hydrogen oxidation process for the synthesis of hydrogen peroxide, was to use supercritical $\mathrm{CO}_{2}$ as a reaction medium. This is because earlier studies with Pd catalysts have indicated that $\mathrm{H}_{2}$ diffusion is a significant problem and this can be expected to be largely overcome by using supercritical media due to the enhanced solubility of $\mathrm{H}_{2}$ (42). Au/ZnO, $\mathrm{Pd} / \mathrm{ZnO}$ and $\mathrm{Au}: \mathrm{Pd} / \mathrm{ZnO}$ catalysts containing $5 \mathrm{wt} \%$ metal were evaluated for the synthesis of hydrogen peroxide using supercritical $\mathrm{CO}_{2}\left(35^{\circ} \mathrm{C}, 9.7 \mathrm{MPa}\right)$. We found that the $\mathrm{Au} / \mathrm{ZnO}$ and $\mathrm{Au}: \mathrm{Pd} / \mathrm{ZnO}$ catalysts exhibited some hydrogen peroxide synthesis, albeit at a low rate. However, the Pd catalyst only generated water as a product. At this temperature it was considered that the hydrogen peroxide formed was relatively unstable with respect to decomposition or hydrogenation (see Scheme 2). Hence, although using supercritical $\mathrm{CO}_{2}$ as the reaction medium may have overcome the diffusion limitation, the inherent instability of hydrogen peroxide at the elevated temperature required to achieve supercritical conditions mitigates against the use of this medium.

Subsequently, experiments were conducted at significantly lower temperatures $\left(2^{\circ} \mathrm{C}\right)$ and the results, shown in Figure 11 , indicate that hydrogen peroxide can be formed at a high rate for the supported $\mathrm{Au}$ catalyst. The selectivity for $\mathrm{H}_{2} \mathrm{O}_{2}$ for the $\mathrm{Au} / \mathrm{Al}_{2} \mathrm{O}_{3}$ catalyst was determined to be $53 \%$. In this case, the catalysts were prepared by impregnation and they were tested for hydrogen peroxide formation at $2^{\circ} \mathrm{C}$ using aqueous methanol as solvent. The supported Au:Pd (1:1 by wt) catalyst produces significantly more than the pure Au catalyst or the Pd catalyst. This indicates a synergistic effect of Pd acting as a promoter for the Au catalyst. To demonstrate that the supported gold catalysts functioned as wholly heterogeneous catalysts, an

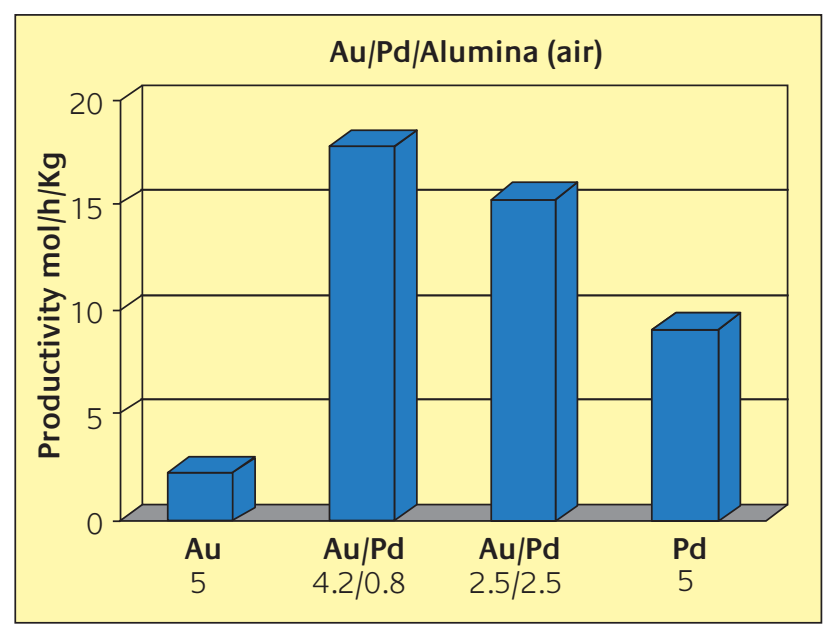

Figure 11

Production of hydrogen peroxide from the reaction of $\mathrm{H}_{2}$ and $\mathrm{O}_{2}$ over $\mathrm{Au}$ and $\mathrm{Au} / \mathrm{Pd}$ catalysts at $2{ }^{\circ} \mathrm{C}$ in an autoclave reactor using aqueous methanol $\left(\mathrm{CH}_{3} \mathrm{OH}, 5.6 \mathrm{~g} ; \mathrm{H}_{2} \mathrm{O} 2.9 \mathrm{~g}\right)$ as solvent with catalyst $(0.05 \mathrm{~g})$, the reactor was purged three times with $\mathrm{CO}_{2}(3 \mathrm{MPa})$ and then filled with $5 \% \mathrm{H}_{2} / \mathrm{CO}_{2}$ and $25 \% \mathrm{O}_{2} / \mathrm{CO}_{2}$ 
experiment was carried out using a supported gold catalyst at $2^{\circ} \mathrm{C}$ and the yield of $\mathrm{H}_{2} \mathrm{O}_{2}$ was determined. Following this reaction, the gold catalyst was removed by careful filtration and the solution was used for a second experiment using $\mathrm{O}_{2} / \mathrm{H}_{2}$. No further $\mathrm{H}_{2} \mathrm{O}_{2}$ was formed and this confirms that the formation of hydrogen peroxide involves gold acting as a wholly heterogeneous catalyst. To determine if the supported Au:Pd catalyst comprises Au:Pd alloy particles or if the two components exist separately, the material was examined by scanning transmission electron microscopy (STEM). Using the annular dark field image, which gives strong atomic number (Z) contrast, it was found that for these catalysts the metal particles range from 2 to $9 \mathrm{~nm}$ in diameter. Energy dispersive X-ray (EDS) point analysis from more than 200 particles have been carried out. This shows that all the particles are alloys and although there is some compositional variation from particle-to-particle, the average composition is $50 \mathrm{wt} \% \mathrm{Au}$ : $50 \mathrm{wt} \%$ Pd as expected.

Our work demonstrates that supported Au catalysts are effective for the direct synthesis of hydrogen peroxide from hydrogen and oxygen. In particular, Au catalysts may provide a significant improvement over Pd catalysts that have been investigated previously (34-38). This clearly represents an exciting new reaction for which gold is a highly effective catalyst.

\section{Concluding comments}

The field of catalysis by gold is just beginning to open up. At present a large amount of effort is focused on the well documented oxidation of $\mathrm{CO}$ at ambient temperature. However, it is clear that supported gold catalyst, whether prepared by co-precipitation, deposition precipitation or impregnation, can be highly effective for other hydrogenation and oxidation reactions. There is, therefore, a rich redox chemistry of gold that we are currently exploring and we can expect new exciting discoveries in the coming years.

\section{References}

1 P.A. Sermon, G.C. Bond and P.B. Wells, J. Chem. Soc., Faraday Trans. 1, 75 (1979) 385.

2 J.E. Bailie and G.J. Hutchings, Chem. Commun.,(1999) 2151.

3 M. Haruta, T. Kobayashi, H. Sano and N. Yamada, Chem. Lett., 4 (1987) 405.

4 G.J. Hutchings, J. Catal., 96 (1985) 292.

5 K. Shinoda, Chem. Lett. (1975) 219.

6 B. Nkosi, N.J. Coville and G.J. Hutchings, Appl. Catal., 43 (1988) 33.

7 B. Nkosi, N.J. Coville, G.J. Hutchings, M.D. Adams, J. Friedl and F. Wagner, J. Catal., 128 (1991) 366.

8 B. Nkosi, M.D. Adams, N.J. Coville and G.J. Hutchings, J. Catal., 128 (1991) 378.
9 G.C. Bond and D.T. Thompson, Catal. Rev.-Sci. Eng., 41 (1999) 319.

10 G.C. Bond and D.T. Thompson, Gold Bull., 33 (2000) 41.

11 J.E. Bailie, H.A. Abdullah, J.A. Anderson, C.H. Rochester, N.V. Richardson, N. Hodge, J.G. Zhang, A. Burrows, C.J. Kiely and G.J. Hutchings, Phys. Chem. Chem. Phys., 3 (2001) 4113.

12 N.A. Hodge, C.J. Kiely, R. Whyman, M.R.H. Siddiqui, G.J. Hutchings, Q.A. Pankhurst, F.E. Wagner, R.R. Rajaram and S.E. Golunski, Catal. Today, 72 (2002) 133.

13 M. Valden, X. Lai and D.W. Goodman, Science, 281 (1998) 1647.

14 H.-G. Boyen, G. Kästle, F. Weigl, B. Koslowski, G. Dietrich, P. Ziemann, J.P. Spatz, S. Rietmüller, T. Hartmann, M. Nöller, G. Smid, M. Garnier and P. Oelhafen, Science, 297 (2002) 1533.

15 N. Lopez and J.K. Nørskov J. Am. Chem. Soc, 124 (2002) 11262.

16 H. Baker, Science, Perspectives, vol 301, 15th August 2003.

17 Q. Fu, H. Saltsburg and M. Flytzani-Stephanopoulos, Science, 301 (2003) 935.

18 B.C. Gates and J. Guzmann, J. Phys. Chem. B, 106 (2002) 7659.

19 B.C. Gates and J. Guzmann, Angew. Chem. Int. Ed., 42 (2003) 690.

20 R. Garcia, M. Besson and P. Gallezot, Appl. Catal. A, 127 (1995) 165.

21 P. Fordham, R. Garcia, M. Besson and P. Gallezot, Stud. Surf. Sci. Catal., 101 (1996) 161.

22 P. Gallezot, Catal. Today, 37 (1997) 405.

23 H. Kimura, K. Tsuto, T. Wakisaka, Y. Kazumi and Y. Inaga, Appl. Catal. A, 96 (1993) 217.

24 H. Kimura, Appl. Catal. A, 105 (1993) 143.

25 S. Carretin, P. McMorn, P. Johnston, K. Griffin, C.J. Kiely and G.J. Hutchings, Phys. Chem. Chem. Phys., 5 (2003) 1329.

26 L. Prati and M. Rossi, J. Catal., 176 (1998) 552.

27 F. Porta, L. Prati, M. Rossi, S. Colluccia and G. Martra, Catal. Today, 61 (2000) 165.

28 C. Bianchi, F. Porta, L. Prati and M. Rossi, Top. Catal., 13 (2000) 231.

29 L. Prati, Gold Bull., 32 (1999) 96.

30 S. Carrettin, P. McMorn, P. Johnston, K. Griffin and G.J. Hutchings, Chem. Commun., (2002) 696.

31 M. Benson and P. Gallezot, Catal. Today, 57 (2000) 127.

32 R.A. Sheldon, Stud. Surf. Sci. Catal., 110 (1997) 151.

33 G. Jenzer, T. Mallet, M. Maciejewski, F. Eigenmann and A. Baiker, Appl. Catal. A., 208 (2001) 125.

34 H.T. Hess in Kirk-Othmer Encyclopedia of Chemical Engineering, Eds. I. Kroschwitz and M. Howe-Grant, Wiley, New York, 13 (1995) 961.

35 J. Van Weynbergh, J.-P. Schoebrichts and J.-C. Colery, US Pat. 5447706 , 1995.

36 B. Zhou and L.-K. Lee, US Pat. 6168775, 2001.

37 J. Wanngard, Eur. Pat. 0816286 Al, 1998.

38 K.T. Chuang and B. Zhou, US Pat. 5338531.

39 T. Hayashi, K. Tanaka and M. Haruta, J. Catal., 178 (1998) 566.

40 P. Landon, P.J. Collier, A.J. Papworth, C.J. Kiely and G.J. Hutchings, Chem. Commun., (2002) 2058.

41 P. Landon, P.J. Collier, A.F. Carley, D. Chadwick, A.J. Papworth, A. Burrows, C.J. Kiely and G.J. Hutchings, Phys. Chem. Chem. Phys., 5 (2003) 1917.

42 G.J. Hutchings, I.H. Stewart and E.G. Derouane "Catalytic reactions at supercritical conditions", Current Topics in Catalysis, 2 (1999) 17. 